\title{
Significance of Timing on Effect of Metaphylactic Toltrazuril Treatment against Eimeriosis in Calves
}

Heidi Larsen Enemark' $₫$, Jan Dahl², Jörg Matthias Dehn Enemark ${ }^{3}$

${ }^{1}$ Department of Veterinary Diagnostics and Research, National Veterinary Institute, Technical University of Denmark, 1870 Frederiksberg C, Denmark

2 Jan Dahl Consult, 4350 Ugerløse, Denmark

${ }^{3}$ Bayer HealthCare, 2300 Copenhagen S, Denmark

\section{Corresponding author:}

Heidi Larsen Enemark

$\triangle$ E-mail: enhi@vet.dtu.dk

\section{Abstract}

In this multicentric, randomised, blinded and placebo-controlled field study, the effect of treatment with toltrazuril (Baycox ${ }^{\circledR}$ Bovis, Bayer) on oocyst excretion, diarrhoea score and weight gain was studied in Danish dairy herds with confirmed history of eimeriosis (coccidiosis) and prevalence of Eimeria bovis and Eimeria zuernii. Three commercial herds and a total of 71 calves, aged 48-135 days, were included. Treatment with a single oral dose of toltrazuril $(15 \mathrm{mg} /$ $\mathrm{kg}$ ) was given after relocation to common pens and one week before expected outbreak of eimeriosis. The effect of treatment was followed by weekly faecal sampling and weighing initially and at the end of a study period of 8 weeks. In Herd 2 and 3 toltrazuril treated calves gained on average $7.95 \mathrm{~kg}$ more than placebo treated calves $(p=0.007)$, and both oocyst excretion and prevalence of Eimeria spp. were significantly reduced the first weeks post treatment. In Herd 1 , by contrast, the farmer made some unforeseen changes in the management which entailed relocation to large deep-litter pens 3-6 weeks post treatment. In addition, many calves were not treated metaphylactically while few calves excreted oocysts when the trial was initiated. Thus, no significant difference in weight gain was found between toltrazuril and placebo treated calves $(p=0.523)$, and the oocyst excretion of toltrazuril treated calves was significantly higher during week 7 and 8. Significant differences in faecal scores were observed between the herds $(p<0.002)$ but not between treatment groups in any of the herds. In conclusion, timing 
of treatment is crucial for optimal effect of metaphylactic toltrazuril treatment on weight gain and oocyst excretion.

\section{Introduction}

Eimeriosis (coccidiosis) in calves is a ubiquitous intestinal infection caused by various Eimeria species of which Eimeria züernii and Eimeria bovis are considered the most pathogenic (Daugschies and Najdrowski, 2005). Bovine eimeriosis is mostly a disease of young calves, typically occurring within the first six month of age (Taylor and Catchpole 1994) but all age groups are susceptible although the disease is primarily a problem in young animals reared under intensive production systems. Experimental infections as well as field studies have continuously shown reduced growth rates of clinically affected calves (e.g. Stockdale et al. 1981; Mundt et al. 2005a). However, eimeriosis may remain subclinical if the infection pressure is low, if the prevalence of highly pathogenic Eimeria spp. is low or if immunity has developed due to previous infection (Cornelissen et al. 1995); and studies have shown that subclinical infection may in fact have a higher economic impact than clinical eimeriosis due to its wider distribution (Daugschies et al. 2007).

Eimeriosis may lead to generalised catarrhal enteritis, thickening of the intestinal mucous membranes and in haemorrhagic diarrhoea through erosion and destruction of the intestinal mucosa (e.g. Friend and Stockdale, 1980). The infection may to some extend be controlled by good hygienic measures and appropriate farm management procedures. However, in highly intensive farming systems with high stocking rates and frequent relocation of the young calves anticoccidial treatment is often necessary to prevent heavy contamination of the environment and major economic losses.

Toltrazuril (Baycox ${ }^{\circledR}$ Bovis) is effective only on intracellular stages of Eimeria spp. (Greif G, 2000), and metaphylactic treatment (treatment in the incubation period of the disease) with toltrazuril is recommended to allow for a simultaneous development of protective immunity along with a significant protection against clinical disease and oocysts shedding (Epe et al. 2005).

A recent study found that eimeriosis is highly prevalent in Danish dairy herds. In herds with calf diarrhoea Eimeria spp. were detected in $60.9 \%$ of the individual calves and in $96.2 \%$ of the herds of which $88.5 \%$ were positive for E. zuernii and/or E. bovis (Enemark et al., 2013). Similar high overall prevalences of Eimeria spp. have been found in many other studies around the World although some European studies have reported remarkably lower prevalences of E. zuernii and E. bovis (Cornelissen et al. 1995; Koutny et al. 2012).

The objective of the current study was to evaluate the clinical and parasitological efficacy of metaphylactic treatment with a single oral dose of toltrazuril in commercial dairy calf-rearing herds in a Danish context.

\section{Material and methods}

\section{Study design}

The experimental design was a polycentric, placebo-controlled, randomised, blinded field study to evaluate the effect of metaphylactic treatment with Baycox ${ }^{\circledR}$ Bovis or placebo of calves housed together in stalls with at least six animals together from an approximate age of 2 months. The observation period was 8 weeks and the effect parameters were bodyweight gain, faecal score and excretion of Eimeria oocysts. Following an initial screening of a large number of dairy herds three herds were enrolled in the study. These herds fulfilled the inclusion criteria of clinical and laboratory confirmed eimeriosis in young calves aged approximately 2 month in group housing.

At the start of the trial all calves were weighed (weight in), a faecal sample was collected from each calf, and the calf was allocated to one of two treatment groups: for each box, calves were stratified 
according to weight or birth date. Subsequently, the first calf was assigned to either treatment 1 or treatment 2 by lottery and the following calves then alternated between the treatments. Thus, the two treatment groups were not separated during the study. Bayer HealthCare Denmark kept a registration of the assignment of the calves to the two groups. This assignment and the identity of the two treatments $(1=$ placebo/Control and $2=$ Baycox ${ }^{\circledR}$ Bovis/Treat) were not disclosed by Bayer HealthCare Denmark until all analyses were completed. The treatment was a single oral dose of $3 \mathrm{ml} / 10 \mathrm{~kg}$ body weight of either placebo (full fat milk) or Baycox ${ }^{\circledR}$ Bovis Vet $5 \%$ (15 mg/kg). Based on pre-screening of the oocyst excretion among calves in the herds the treatment was initiated one week before expected outbreak of eimeriosis. At termination of the experiment all calves were weighed again (weight out).

\section{Herds and animals}

\section{Herd 1, pre-study information:}

Jersey dairy herd with 480 cows in milking. Calves received $3 \mathrm{~L}$ colostrums shortly after birth and within 24 hours post partum they were moved to clean, straw-bedded pens with 3 concrete walls of $1.5 \mathrm{~m}$ in height in a stable solely used for calves. Groups of six calves were housed in each pen and remained together in this pen until 16-18 weeks of age. At this time they were moved to another building with two large straw-bedded deep-litter pens holding around 40-60 calves in each section. Although this rearing system should predict eimeriosis after the movement to the larger deep-litter pens, it was a recurrent experience in this herd, that approximately $50 \%$ of the calves in each of the smaller groups developed clinical eimeriosis with diarrhoea, emaciation and unthriftiness. Thus, to determine the best time of treatment, faecal samples from 30 calves, aged 52 to 121 days, were examined prior to the start of the experiment. Eight of these calves excreted more than 1000 oocysts per gram of faeces (opg). The youngest of these Eimeria positive calves excreted $71,000 \mathrm{opg}$, of which $10 \%$ were E.zuernii, at an age of 68 days. As the prepatency period of E. zuernii is 17-24 days (Mundt et al., 2005a) and based on this screening it was thus decided to start metaphylactic treatment at approximately 7 weeks of age. With an observation period of 8 weeks the study would then be completed before the calves were transferred to the deep-litter pens.

\section{Course of the study:}

Over a period of five weeks 51 calves in nine pens were included in the study. Twenty-five calves received placebo treatment and 26 calves received metaphylactic Baycox ${ }^{\circledR}$ Bovis treatment. The calves were approximately 50 days old with a mean body weight of around $50 \mathrm{~kg}$ when they were enrolled in the study (see Table 1 for details). During the course of the experiment the number of new-born calves exceeded the capacity of the calf stable. Consequently, the farmer moved the calves from the first two pens to the deep-litter pen already three weeks after start when they were aged 10-11 weeks, and calves from the remaining pens were moved 4 to 6 weeks post treatment. Since all calves were individually ear-tagged this unexpected movement of the calves did not have any influence on the faecal sampling, but it was evident that the infection pressure in the deep-litter pens was much higher compared with the smaller pens, and many calves developed diarrhoea. Although the farmer had agreed to treat all calves with clinical signs of eimeriosis he did not do so as he feared he would interfere with the experiment. As soon as the study veterinarian became aware of this problem all calves from the first 7 pens were treated with Baycox ${ }^{\circledR}$ Bovis. This was done between 5 and 9 weeks after the start (i.e. one week after the calves were weighed out of the experiment). At this time all the calves were also weighed out of the study. The calves from the remaining two pens were moved two weeks later ( 6 weeks post treatment), at which time they were weighed out of the study. 


\section{Herd 2, pre-study information:}

Holstein dairy herd with 230 cows in milking. Calves were housed in individual straw-bedded outdoor huts from birth to approximately 4 weeks of age, and subsequently housed in outdoor huts in groups of three. At an age of 8-12 weeks, calves from three groups were merged and housed in a slatted floor pen with bed stalls. Clinical signs of eimeriosis appeared in up to $50 \%$ of the calves two to three weeks after relocation to the communal pen, and massive excretion of Eimeria oocysts were detected in these calves.

\section{Course of the study:}

One pen, holding calves $(\mathrm{N}=9)$ aged approximately 90 days with a mean body weight of about $100 \mathrm{~kg}$ (see Table 1 for details), was included in the study, which started four days after the calves had been relocated to the slatted floor pen. Five calves received placebo treatment and four calves were treated metaphylactically with Baycox ${ }^{\circledR}$ Bovis. There were no unforeseen changes in the study design, and the calves were weighed out 59 days later.

\section{Herd 3, pre-study information:}

Holstein dairy herd with 170 cows in milking. Calves were housed in individual straw-bedded huts from birth to approximately 8 weeks of age. At this age, groups of 9 to 12 calves were moved into a calf pen with individual huts and a communal straw-bedded area. Pre-study samples showed massive excretion of Eimeria oocysts two to three weeks after relocation into this pen.

\section{Course of the study:}

One pen holding calves $(\mathrm{N}=11)$ aged around 70 days with a body weight of roughly $80 \mathrm{~kg}$ (see Table 1 for details) was included in the study, which started one week after the calves had been moved to the communal pen. Due to construction work, the calves were slightly older than they would usually be at the time of relocation. Six calves received the placebo treatment and five calves received metaphylactic Baycox ${ }^{\circledR}$ Bovis treatment. There were no unforeseen changes in the study design, and the calves were weighed out 56 days later.

\section{Faecal examination}

Faecal samples were collected at weakly intervals and stored at $5^{\circ} \mathrm{C}$ until analysis within 3 days. The oocysts were quantified at the National Veterinary Institute by a DANAK accredited modified McMaster technique with a sensitivity of 5 opg (Henriksen and Aagaard 1975; Henriksen and Korsholm 1984). Eimeria oocysts from all individual samples were examined at 400x magnification and identified to species level without sporulation using the morphological criteria described by Eckert et al. (1995). For each sample the total opg and the relative percentage of $E$. bovis or $E$. zuernii were determined in addition to visual scoring of faecal consistency on a scale from one to five (1: normal; 2 : soft; 3 : liquid; 4: watery; 5 : watery with blood and/or intestinal tissue).

\section{Statistical analysis \\ Body weight}

Data were analysed using proc mixed (SAS Inst.). All data were analysed in one model:

Weight out $=+{ }_{1}{ }^{*}$ Treat $+{ }_{2}{ }^{*} \mathrm{Herd} 1+{ }_{3}{ }^{*}$ Herd2 $+{ }_{3}{ }^{*}$ Weight in

Pen was included as a random factor, and the effect of Treat, i.e. placebo or Baycox ${ }^{\circledR}$ Bovis, was allowed to vary on the pen-level (random slopes model). Possible interactions between treatment and herd were investigated, and there was a significant interaction between herd and treatment. This interaction was further investigated to explore treatment effects in the three herds: the above mentioned model was simplified to include only the intercept and interaction term between herd and treatment, start weight and the described random effects. A number of contrast statements were used to explore differences.

\section{Oocyst excretion}

Dohoo et al. (2003) describe a methodology for handling overdispersed data with an excess of zeros. Count data are generally assumed to follow a Poisson-distribution. One method to account for overdispersed count-data is to use a negative binomial regression model. Furthermore, this method 
can be expanded to the handling of excess zeros. Excess zeros are problematic when there are two processes by which zero counts can arise. In the present study, zeros may have arisen from two different processes: 1) the calf is "truly negative", i.e. no Eimeria oocyst are detected, in which case all samples will be negative no matter how many samples that are examined from the calf; or 2) the calf is positive, but the number of oocysts per gram is subject to a Poisson distribution.

Zero-inflated models handle the modelling process of two distributions, one following a binomial distribution, whether the calf is positive or not, the other being a count-process, following the specified distribution for counts. In this case a negativebinomial distribution. SAS proc NLMIXED (SAS 9.1) was used for the modelling process. Data were modelled for each sampling round simultaneously for all three herds except for cases where it was obviously irrelevant to model excess zeros. In these cases proc genmod (SAS 9.1) was used. When there were no positive samples in Treat and Control calves in the same sampling round, results from that particular herd were not included for that specific herd. P-values were obtained by a likelihoodratio test, comparing models with treatment-effects for the binomial distribution, the negative binomial distribution, and a baseline model without treatment effect.

\section{Faecal score}

Data were analysed using a cumulative logit model assuming proportional odds. Proc genmod (SAS 9.1) was used. The model included herd and treatment effect as explanatory factors.

\section{Results}

\section{Body weight}

The mean weight gains of calves treated with either Baycox ${ }^{\circledR}$ Bovis or placebo in the different herds are shown in Table 1. A positive effect of metaphylactic Baycox ${ }^{\circledR}$ Bovis treatment on weight gain was shown in Herd 2 and Herd 3, and the combined effect was clearly significant $(p=0.007)$ corresponding to a mean difference in weight gain of

Table 1 Observational findings for the treatment groups in each of three study herds at the start of the trial.

\begin{tabular}{|c|c|c|c|c|c|c|}
\hline \multirow{2}{*}{ Variable } & \multicolumn{2}{|c|}{ Herd 1} & \multicolumn{2}{|c|}{ Herd 2} & \multicolumn{2}{|c|}{ Herd 3} \\
\hline & Treat & Control & Treat & Control & Treat & Control \\
\hline $\begin{array}{l}\text { Percentage of calves } \\
\text { excreting Eimeria spp. } \\
\text { oocysts }\end{array}$ & 8 & 20 & 67 & 25 & 80 & 100 \\
\hline $\begin{array}{l}\text { Percentage of calves } \\
\text { with opg } \geq 500\end{array}$ & 7.7 & 12.5 & 0 & 0 & 40.0 & 20.0 \\
\hline $\begin{array}{l}\text { Percentage of calves } \\
\text { with } E \text {. zuernii and } \\
\text { E. bovis opg } \geq 500\end{array}$ & 0 & 0 & 0 & 0 & 0 & 0 \\
\hline $\begin{array}{l}\text { Percentage of calves } \\
\text { with faecal score } \geq 3\end{array}$ & 0 & 37.5 & 0 & 0 & 20.0 & 0 \\
\hline $\begin{array}{l}\text { Body weight (kg) } \\
\text { (mean, confidence } \\
\text { intervals) }\end{array}$ & $\begin{array}{c}50.11 \\
(47.49-2.73)\end{array}$ & $\begin{array}{c}51.46 \\
(48.50-54.42)\end{array}$ & $\begin{array}{c}105.75 \\
(76.28-135.22)\end{array}$ & $\begin{array}{c}106.20 \\
(76.28-135.22)\end{array}$ & $\begin{array}{c}80.20 \\
(63.88-96.52)\end{array}$ & $\begin{array}{c}80.00 \\
(63.17-96.83)\end{array}$ \\
\hline $\begin{array}{l}\text { Age at treatment } \\
\text { (days) (mean, } \\
\text { confidence intervals) }\end{array}$ & $\begin{array}{c}50.63 \\
(49.14-52.11)\end{array}$ & $\begin{array}{c}50.57 \\
(48.80-52.33)\end{array}$ & $\begin{array}{c}89.75 \\
(76.16-103.3)\end{array}$ & $\begin{array}{c}90.00 \\
(77.55-102.4)\end{array}$ & $\begin{array}{c}69.00 \\
(45.23-92.77)\end{array}$ & $\begin{array}{c}69.50 \\
(52.62-86.38)\end{array}$ \\
\hline
\end{tabular}




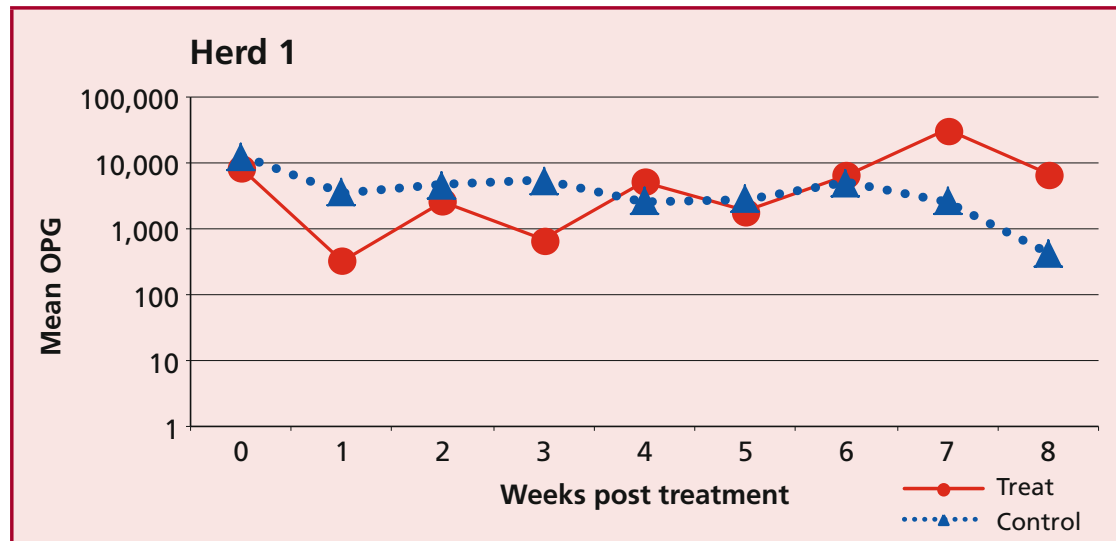

Fig. 1 Mean total oocysts per gram of faeces (opg) in calves $(\mathrm{N}=71)$ from Herd 1-3. Red solid lines and circles indicate opg values of Baycox ${ }^{\circledR}$ Bovis treated calves. Blue dotted lines and triangles indicate opg values of placebo treated calves..

\section{Herd 2}

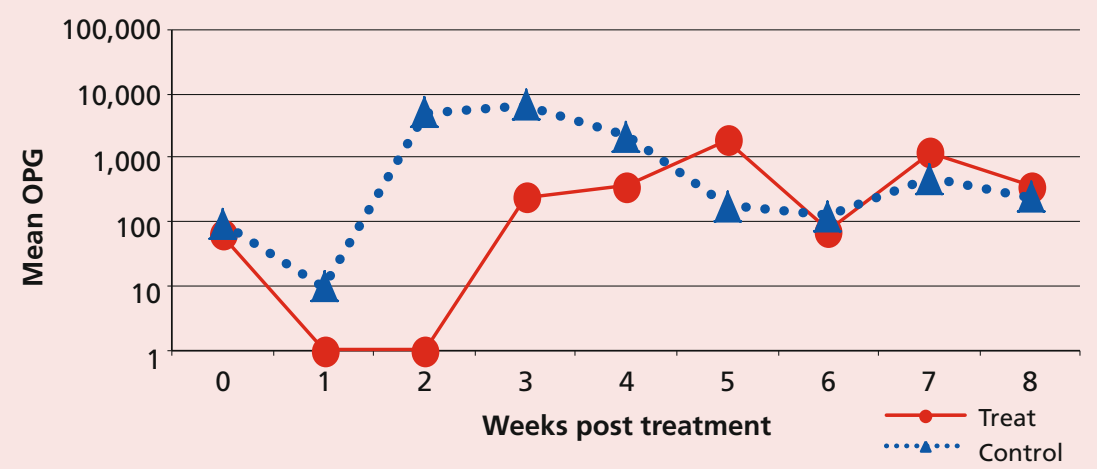

Herd 3

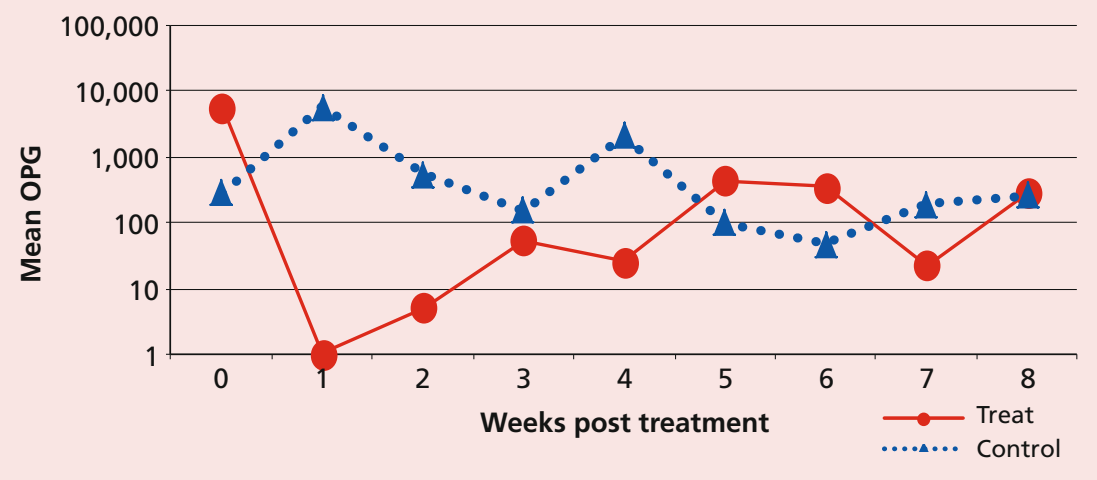

$7.95 \mathrm{~kg}$ between Baycox ${ }^{\circledR}$ Bovis and placebo treated calves during the study period of eight weeks. In contrast, no significant effect of Baycox ${ }^{\circledR}$ Bovis treatment was found in Herd 1 as equal weight gains were observed in Baycox ${ }^{\circledR}$ Bovis treated calves and controls $(p=0.523)$. In accordance with these observations the treatment effect on weight in Herd 1 differed significantly from effects in
Herd 2 and $3(p=0.009)$, whereas the treatment effect could be assumed to be equal for Herds 2 and $3(p=0.50)$. Check for residuals were performed, and revealed no violation of assumptions for linear regressions. Residuals were normally distributed, and plots showed no violation of equal variances for predictors. 


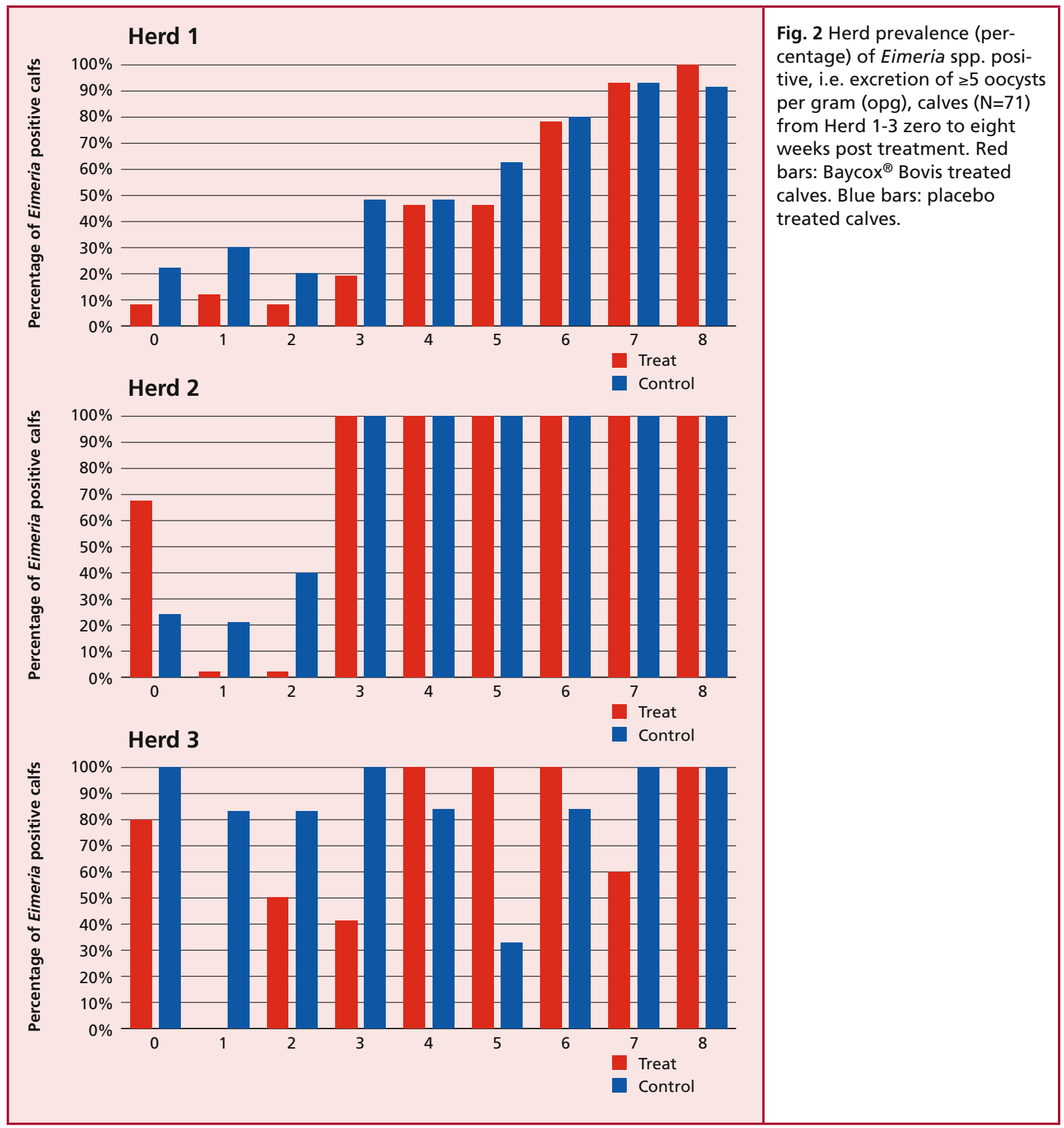

\section{Oocyst excretion}

Mean excretion of Eimeria spp. oocysts in the treatment groups is presented for each of the three study herds in Figure 1, while the percentage of calves in which Eimeria spp. oocysts were detected, i.e. calves with $\geq 5 \mathrm{opg}$, is shown in Figure 2 .

In Herd 1, less than $50 \%$ of the calves excreted oocysts at the time of metaphylactic treatment and up to week four of the experiment, and only four of the 25 placebo treated calves excreted more than 1000 opg during the first three weeks post treatment. In contrast, all calves ( $100 \%)$ were excreting Eimeria spp. oocysts in Herd 2 by three weeks post treatment, and $90 \%$ of the calves in Herd 3 were excreting oocysts at the time of Baycox ${ }^{\circledR}$ Bovis treatment. 


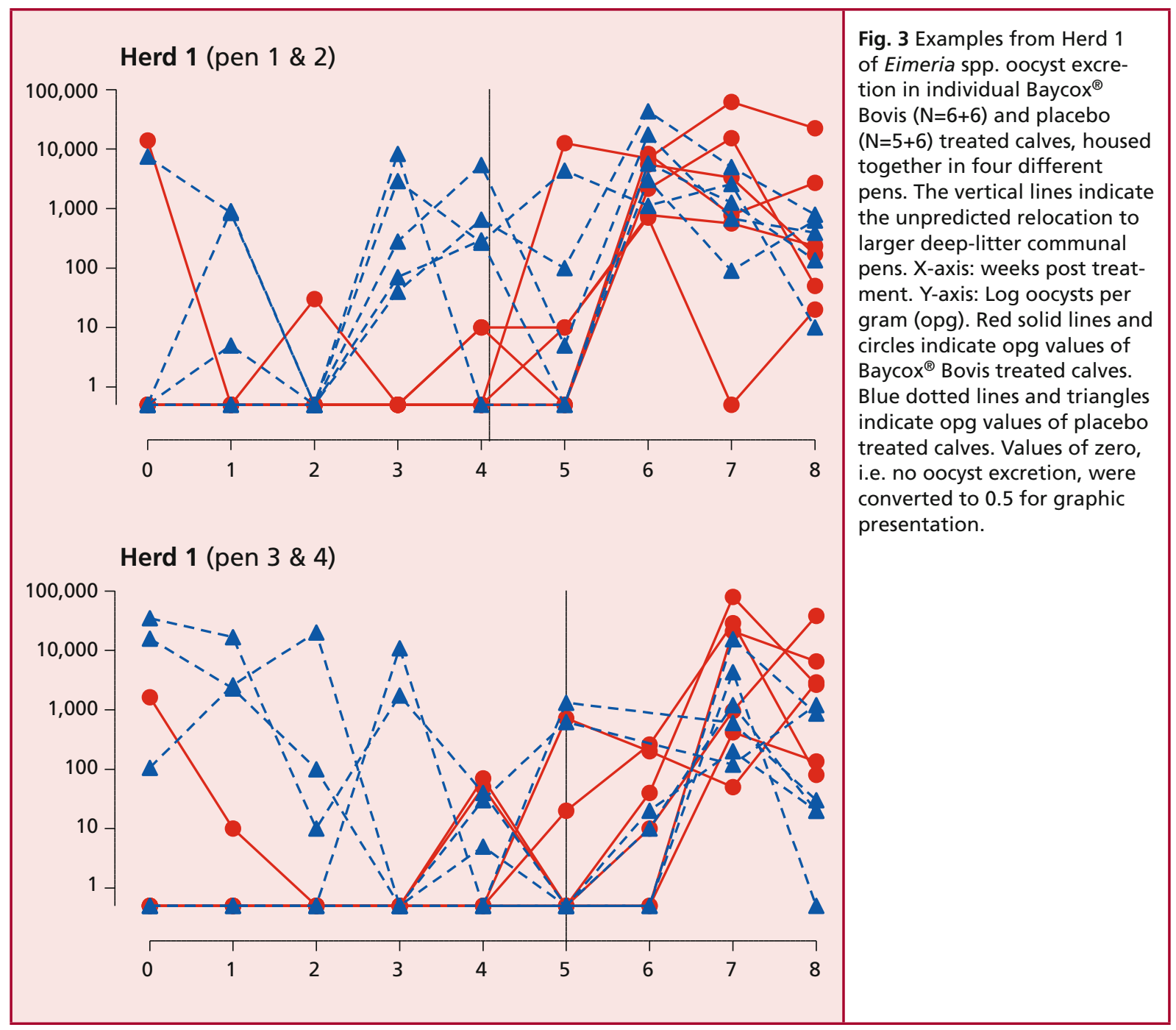

Corresponding to the distinct differences in prevalence of Eimeria spp. oocysts between Herd 1 and the other herds, the mean oocyst excretion throughout the study period showed very different patterns in Herd 1 compared to Herd 2 and 3 (Figure 1). While the mean oocyst excretion remained high and relatively stable around 1000-10,000 opg in both Baycox ${ }^{\circledR}$ Bovis and placebo treated calves in Herd 1, the oocyst excretion dropped to about zero the first two weeks post treatment in Baycox ${ }^{\circledR}$ Bovis treated calves in Herd 2 and 3. From week three, the oocyst excretion of Baycox ${ }^{\circledR}$ Bovis treated calves in Herd 2 and 3 then gradually increased to the same level as observed in placebo treated calves in these herds. Differences across the treatment groups of all herds were significantly different in week 1 and 3 post treatment ( $\mathrm{p}=0.004$ and 0.005 , respectively) and close to significant in week $2(p=0.13)$.

As concerns the distribution of highly pathogenic Eimeria spp. in the herds, the mean oocyst excretion of E. zuernii and E. bovis throughout the first 5 weeks post treatment was similar in all herds with around $1000 \mathrm{opg}$ for each of the species except for Baycox ${ }^{\circledR}$ Bovis treated calves in Herd 2 and 3, where the oocyst excretion of these species was significantly reduced during 5 weeks post treatment $(p<0.05)$ after which the excretion increased to 
reach the same level (around $100 \mathrm{opg}$ ) as observed in the placebo treated calves by the end of the study period. Although the excretion levels were low in Herd 2 and 3 the prevalence of both species was above $90 \%$ in Herd 2, and E. bovis was detected in $60 \%$ the Baycox ${ }^{\circledR}$ Bovis treated calves and $>80 \%$ of the placebo treated calves in Herd 3 towards the end of the study. In contrast, the prevalence of E. bovis only reached approximately $40 \%$ in Herd 1 while around $50 \%$ of the calves excreted E. zuernii despite mean oocyst excretion of around 10,000 opg (data not shown).

In Herd 1 a considerable variation in oocyst excretion was observed between the 9 different calf pens. Examples of oocyst excretion in individual calves exposed to unpredicted relocation to larger deeplitter communal pens during the study period are presented in Figure 3, in which a distinct increase in oocyst excretion to values around 10,000 opg is evident in Baycox ${ }^{\circledR}$ Bovis treated calves approximately two weeks after the relocation resulting in significantly higher $(\mathrm{p} \leq 0.003)$ oocyst excretion at the last two samplings compared to placebo treated calves as well as calves in the other study herds. In contrast, the oocyst excretion of placebo treated calves fluctuated throughout the study period but remained at a high level.

\section{Faecal score}

Significant differences in faecal scores were observed between the three herds $(p<0.0002)$ but no significant differences in faecal scores were found between Baycox ${ }^{\circledR}$ Bovis and placebo treated calves (data not shown).

\section{Discussion}

\section{Effect of treatment}

In the present study, we report the effect of a single oral treatment of dairy calves with Baycox ${ }^{\circledR}$ Bovis, $15 \mathrm{mg} / \mathrm{kg}$ body weight, on parasitological and relevant production parameters. In accordance with previous studies (for example Mundt et al. 2005a ) the present multicentric field trial demonstrated a clear and significant effect of Baycox ${ }^{\circledR}$ Bovis treatment on weight gain and oocyst excretion in Herd 2 and 3 , where the study was executed according to the planned design. Over the course of this study, i.e. eight weeks, Baycox ${ }^{\circledR}$ Bovis treatment caused a mean increased weight gain of $7.97 \mathrm{~kg}$ in the treated calves compared with calves that received placebo. In contrast, there was no significant difference in weight gain between Baycox ${ }^{\circledR}$ Bovis and placebo treated calves in Herd 1, and the mean oocyst excretion remained high in both groups throughout the whole study period; however, with lower oocyst excretion the first weeks post treatment and significantly higher oocyst excretion at the end of the trial in Baycox ${ }^{\circledR}$ Bovis treated calves compared with the placebo treated calves.

In Herd 2 and 3, at the time of treatment, one week before expected outbreak of clinical eimeriosis, the majority of the calves excreted low levels of Eimeria spp. oocysts and only one calf had a faeces score of $\geq 3$. In Herd 1 , on the other hand, few calves $(<15 \%)$ excreted oocysts when the trial was initiated, and throughout the first three weeks post treatment only four (16\%) of the 25 placebo treated calves excreted more than $1000 \mathrm{opg}$. This suggests that the treatment cannot be regarded as metaphylactic while the infection was hardly present, and thus the calves were not treated during the prepatent period.

\section{Importance of timing}

The overall aim of the present study was to study the effect of toltrazuril treatment of calves in commercial dairy herds in a Danish context. For this reason three herds with a history of clinical eimeriosis were selected, and great care was taken to predict the expected time of infection in each of the herds. Despite all efforts to carry out the trial according to a predetermined plan, one of the farmers, who provided 51 of the 71 calves in the experiment, made some unforeseen changes in management routines. This meant that the time of exposure to high infection pressure was 
Table 2 LSMEANS estimates of weight gain and differences in weight gain 8 weeks post treatment of calves $(\mathrm{N}=71)$ from three Danish dairy herds treated with Baycox® Bovis (Treat) or placebo (Control).

\begin{tabular}{|c|c|c|c|c|c|}
\hline $\begin{array}{c}\text { Herd } \\
\text { (number of calves) }\end{array}$ & $\begin{array}{c}\text { Treat }(\mathbf{k g}) \\
\text { mean }(\mathrm{Cl})\end{array}$ & $\begin{array}{c}\text { Control }(\mathbf{k g}) \\
\text { mean }(\mathrm{Cl})\end{array}$ & $\begin{array}{c}\text { Difference }(\mathbf{k g}) \\
\text { mean }(\mathrm{Cl})\end{array}$ & p-value & p-value combined \\
\hline $1(\mathrm{~N}=51)$ & $26.12(21.26-30.98)$ & $27.18(22.38-31.98)$ & $-1.06(-4.31-2.19)$ & 0.523 & \\
\hline $2(\mathrm{~N}=9)$ & $43.6(29.00-58.23)$ & $33.67(19.21-48.14)$ & $9.94(2.21-17.67)$ & 0.020 & \multirow{2}{*}{0.007} \\
\hline $3(\mathrm{~N}=11)$ & $52.64(39.30-65.99)$ & $46.31(33.06-59.57)$ & $6.33(-0.65-13.30)$ & 0.088 & \\
\hline
\end{tabular}

Cl: $95 \%$ confidence intervals

unpredictable and therefore the calves were not treated at the optimal time.

Previous studies have demonstrated the importance of timing of treatment against eimeriosis. Ghanem et al. (2008) showed that metaphylactic toltrazuril treatment (the first day of oocyst excretion) reduced the opg and increased the body weight gain compared to later treatment timings. Likewise, Epe et al. (2005) found that metaphylactic toltrazuril treatment of grazing calves infected with $E$. alabamensis resulted in an increased weight gain of $7.3 \mathrm{~kg}$ compared with therapeutic treatment which caused an increased weight gain of $3.4 \mathrm{~kg}$ compared with placebo treated controls. In addition, a study by Jonsson et al. (2011) of immunopathological changes in calves experimentally infected with $E$. bovis and E. zuernii demonstrated that toltrazuril, $15 \mathrm{mg} / \mathrm{kg}$ body weight, given 14 days post infection reached an efficacy of $99 \%$ within three days of treatment and remained above this level for six days; however, allowing the development of a normal or enhanced immune response to infection. In fact, Johnson et al., (2011) showed that expression of the genes coding for the antiinflammatory cytokines interleukin-2 (IL-2), interleukin-10 (IL-10) in the ileum and tumor necrosis factor (TNF) $-\alpha$ in the colon were elevated in toltrazuril treated calves. Similarly, Steinfelder et al. (2005) showed that toltrazuril treatment of mice experimentally infected with $E$. falciformis terminated the ongoing disease without interfering with the establishment of protective immunity against challenge infections.
When the present trial was initiated calves were younger in Herd 1, around 50 days of age, compared with approximately 80 and 100 days in the other two herds; and throughout the first four weeks of the study few calves excreted oocysts (Table 1; Figure 2). Thus, several of the calves in the 9 separate pens included in the study may not have been exposed to Eimeria spp. oocysts, and Baycox ${ }^{\circledR}$ Bovis treatment may have contributed further to reduction of the infection pressure, leaving the calves vulnerable to the high levels of contamination in the deep litter pens that they were moved to at various ages from three to six weeks post treatment as indicated in Figure 3. Despite the low prevalence of eimeriosis in Herd 1 at the time of treatment some Eimeria spp. infections with high intensity were nevertheless present, and the opg levels in Herd 1 were indeed significantly higher $(\mathrm{P}=0.003)$ at the last two samplings compared with the other herds. Additionally, the placebo treated calves in Herd 1 experienced a slightly larger weight gain than the Baycox ${ }^{\circledR}$ Bovis treated calves; however, this difference was by no means significant. Likewise, there were no differences in faecal consistency (data not shown), which altogether indicates that no harm was done by treating the calves at a time of low prevalence. The results from Herd 1 are, nevertheless, a clear indication that coccidiosis in a herd may vary with changes in management, and that any changes in routines may also affect the optimal time of metaphylactic treatment against coccidiosis. On the other hand, the results from Herd 2 and 3 showed that, if given at the correct time, the Baycox ${ }^{\circledR}$ Bovis treatment resulted 
in significantly higher weight gain in the treated calves, but still allowed infection to take place and the oocyst excretion to reach the same low level as observed in the placebo treated calves towards the end of the study period.

Although anticoccidial resistance is known in poultry production (Chapman et al., 2013) resistance against anticoccidial drugs has not yet been reported in Eimeria spp. of mammals. Nevertheless, the possible development of resistance is a course of concern considering the widespread distribution and huge economic importance of eimeriosis in lifestock production (Andrews T, 2008; Lassen and Østergaard, 2012). In this context, it is important to bear in mind that apparent drug failure does not necessarily entail resistance but may simply be due to improper timing of the treatment as shown in the present study.

In conclusion, this field study failed to produce data on the beneficial effect of Baycox ${ }^{\circledR}$ Bovis in Herd 1 due to some unforeseen changes in the management while significant results in support of a positive effect of metaphylactic treatment were observed in Herd 2 and 3. Altogether the Baycox ${ }^{\circledR}$ Bovis treated calves in these two herds gained on average $7.95 \mathrm{~kg}$ more than the placebo treated calves over a period of eight weeks. However, since the total number of calves in Herd 2 and 3 was rather limited these results must be evaluated with caution. The beneficial effect of Baycox ${ }^{\circledR}$ Bovis treatment on oocyst excretion, faeces score and weight gain in calves has nevertheless been demonstrated convincingly by others (Epe et al., 2005; Mundt et al, 2005a,b; Veronesi et al., 2011; Veronesi et al., 2013). Thus, the main conclusion from the present study is that proper timing of treatment is crucial. To benefit from Baycox ${ }^{\circledR}$ Bovis treatment against eimeriosis the calves should be treated metaphylactically i.e. one to two weeks post infection (Mundt et al., 2005a), and great care should be taken to identify the time of infection/ massive exposure to Eimeria spp. oocysts to allow for appropriate timing. If neglected, the treatment may be wasted and in worst case, if treated to early, the calves might be more vulnerable to massive infection later in life. Therefore, knowledge of farm management is vital in each treatment situation and accurate diagnostic procedures, preferably including quantification and identification of the Eimeria species present at farm-level, should be employed to determine the typical time of infection in each farm.

\section{Acknowledgements}

Participating farmers are thanked for their support in this study and laboratory technician Boi-Tien Thi Pham is acknowledged for skilled technical assistance.

\section{Disclosure statement}

Bayer HealthCare, Denmark provided financial support for this study. Heidi L Enemark has occasionally presented research on coccidiosis at Bayer seminars. The authors declare that all scientific aspects of the study including study design and interpretation of results were not influenced by Bayer.

\section{Compliance statement}

The studies reported here were performed in compliance with current applicable national laws and regulations. 


\section{References}

Andrews T (2008) The costs of coccidiosis. Veterinary Practice, August 2008:28-29

Cornelissen AWCA, Verstegen $\mathrm{R}$, van den Brand $\mathrm{H}$, Perie NM, Eysker M, Lam TJGM, Pijpers A (1995) An observational study of Eimeria species in housed cattle on Dutch dairy farms. Vet Parasitol 56:7-16

Daugschies A, Agneessens J, Goossens L, Mengel H, Veys $P$ (2007) The effect of a metaphylactic treatment with diclazuril (Vecoxan ${ }^{\circledR}$ ) on the oocyst excretion and growth performance of calves exposed to a natural Eimeria infection. Vet Parasitol 149:199-206

Chapman HD, Barta JR, Blake D, Gruber A, Jankins M, Smith NC, Suo X, Tomley FM (2013) A selective review of advances in coccidiosis research. Adv Parasitol 83:93-171

Daugschies A, Agneessens J, goossens L, Mengel H, Veys P (2007) The effect of a metaphylactic treatment with diclazuril $\left(\operatorname{Vecoxan}{ }^{\circledR}\right)$ on the oocyst excretion and growth performance of calves exposed to a natural Eimeria infection. Vet Parasitol 149:199-206

Daugschies A, Najdrowski M (2005) Eimeriosis in cattle: current understanding. J Vet Med B Infect Dis Vet Public Health 52(10):417-427

Eckert J, Taylor M, Catchpole J, Licois D, Coudert P, Bucklar H (1995) Morphological characteristics of oocysts. In: Eckert J, Braun R, Shirley MW, Coudert P (eds) Biotechnology guidelines on techniques in coccidiosis research. European Commission, Luxembourg, pp 103-119

Enemark HL, Dahl J, Enemark JMD (2013) Eimeriosis in Danish dairy calves - correlation between species, oocyst excretion and diarrhoea. Parasitol Res 112 Suppl 1:169-176

Epe C, von Samson-Himmelstjerna G, Wirtherle N, von der Heyden V, Welz C, Beening J, Radeloff I, Hellmann K, Schnieder T, Krieger K (2005) Efficacy of toltrazuril as a metaphylactic and therapeutic treatment of coccidiosis in first-year grazing calves. Parasitol Res 97:S127-S133

Friend SCE, Stockdale PHG (1980) Experimental Eimeria bovis infection in calves: a histopathological study. Can J Comp Med 44:129-140

Ghanem MM, Radwaan ME, Moustafa AMM, Ebeid MH (2008) Comparative therapeutic effect of toltrazuril, sulphadimidine and amprolium on Eimeria bovis and Eimeria zuernii given at different times following infection in buffalo calves (Bubalus bubalis). Prev Vet Med 84:161-170
Greif G (2000) Immunity to coccidiosis after treatment with toltrazuril. Parasitol Res 86:787-890

Henriksen SA, Aagaard K (1975) A simple flotation and McMaster technique. Nordic Vet Med 28:392-397. Article in Danish

Henriksen SA, Korsholm H (1984) Parasitological examination of faecal samples. Construction of a simple counting chamber. DVT 84:49-64. Article in Danish

Jonnsson NN, Piper EK, Gray CP, Deniz A, Constantinoiu CC (2011) Efficacy of toltrazuril 5\% suspension against Eimeria bovis and Eimeria zuernii in calves and observations on the associated immunopathology. Parasitol Res 109:S113-S128

Koutny H, Joachim A, Tichy A, Baumgartner W, (2012) Bovine Eimeria species in Austria. Parasitol Res 110:1893-1902

Lassen B, Østergaard S (2012) Estimation of the economical effects of Eimeria infections in Estonian dairy herds using a stochastic model. Prev Vet Med 106:258-265

Mundt H-C, Bangoura B, Rinke M, Rosenbusch M, Daugshies A (2005a) Pathology and treatment of Eimeria zuernii coccidiosis in calves: investigations in an infection model. Parasitol Int 54: 223-230

Mundt H-C, Bangoura B, Mengel H, Keidel J, Daugshies A (2005b) Control of clinical coccidiosis of calves due to Eimeria bovis and Eimeria zuernii with toltrazuril under field conditions. Parasitol Res 97:134-142

Steinfelder S, Lucius R, Greif G, Pogonka T (2005) Treatment of mice with the anticoccidial drug toltrazuril does not interfere with the development of a specific cellular immune response to Eimeria falciformis. Parasitol Res 97:458-465

Stockdale PHG, Bainborough AR, Bailey CB, Niilo L (1981) Some pathophysological changes associated with infection of Eimeria zuernii in calves. Can J comp Med 45:34-37

Taylor MA, Catchpole J (1994) Coccidiosis of domestic ruminants. Appl Parasitol 35:73-86

Veronesi F, Diaferia M, Viola O, Piergili Fioretti D (2011) Long-term effect of toltrazuril on growth performances of dairy heifers and beef calves exposed to natural Eimeria zuernii and Eimeria bovis infections. Vet J 190 (2):296-299

Veronesi F, Nisoli L, Diaferia M, Falcini R, Ficola E, Fioretti DP (2013) Influence of a metaphylactic treatment with Baycox ${ }^{\circledR}$ Bovis on the reproductive performances of Fresian heifers: a preliminary study. Parasitol Res 112, 2137-2142 